\title{
O Território da Doença Relacionada ao Trabalho: o corpo e a medicina nas LER
}

\author{
MARILENE AFFONSO ROMUALDO VERTHEIN \\ CARLOS MINAYO GOMEZ
}

\section{Resumo}

O texto toma como referência a classificação das Lesões por Esforços Repetitivos na categoria de doença relacionada ao trabalho, datada de 1997, quando o Instituto Nacional de Seguridade Social investia na mudança do nome LER para DORT (Distúrbios Osteomusculares Relacionados ao Trabalho). São discutidas as estratégias da negação do nexo como uma produção de silêncio do corpo que adoece em função do trabalho. Apresentam-se o contexto histórico da conceituação de corpo e de doença e as várias leituras que, ao se atualizarem, vão compondo e decompondo os movimentos de criação e/ou cristalização desse território. Finalmente, aponta-se a doença como resistência do corpo aos seus constrangimentos.

Palavras-chave: LER; DORT; subjetividade; saúde do trabalhador; perícia médica. 


\section{Introdução}

A classificação das Lesões por Esforços Repetitivos na categoria de doença relacionada ao trabalho ocorreu em 1997, quando o Instituto Nacional de Seguridade Social investiu na mudança de nome de LER para DORT (Distúrbios Osteomusculares Relacionados ao Trabalho). A mudança, que foi discutida com profissionais de saúde, pesquisadores e sindicatos, apontava para o desdobramento da análise desse processo de adoecimento no âmbito da psicossociologia, da epidemiologia e da ergonomia. Tal procedimento atenderia as reivindicações de médicos e trabalhadores para que se desse mais atenção ao estado de sofrimento psíquico desses pacientes.

A denominação doença relacionada ao trabalho destacou-se na década de 1980, quando os trabalhadores lutavam por obter reconhecimento e indenização acidentária pelos distúrbios psíquicos que os acometiam em função de suas condições de trabalho. Reivindicavam que as enfermidades físicas ou mentais fossem classificadas como doenças do trabalho, se desenvolvidas em função das atividades realizadas pelos trabalhadores. O termo DORT parecia atender a essa expectativa, mas a reapropriação desse território pelo INSS, nos anos 90, reverteu a idéia, enfatizando com o conceito de distúrbio a noção de uma doença adquirida por predisposição do sujeito. Esse deslocamento coloca em questão a decisão, também do INSS (em 1987 e 1991), de que as LER fossem classificadas como doenças do trabalho.

Entendemos como "território da doença relacionada ao trabalho" um espaço de prática - vivências, comportamentos, investimentos, percepções. São formas de pensar e agir que constróem saber/poder, como também forças de resistência para recompor determinadas relações sociais. Queremos problematizar, aí, as estratégias da negação do nexo das LER como uma produção de silêncio do corpo que adoece em função do trabalho. Tal caminho exige pensar o vigor do contexto histórico na conceituação de corpo e de doença, que se atualizam na composição ou decomposição do movimento desse território.

Tomando como fonte de informação os documentos específicos elaborados pelo Ministério da Previdência e Assistência Social (INSS), podemos visualizar alguns conceitos utilizados por ele para melhor entendermos sua definição de doença do trabalho e de doença relacionada ao trabalho, considerando, principalmente, seus aspectos de diferenciação.

A Portaria $\mathrm{n}^{\circ} 4.062$, de 06 de agosto de 1987, reconhece a tenossinovite como doença do trabalho. Categoria definida para a doença: "adquirida ou 
desencadeada em função de condições especiais em que o trabalho é realizado e com ele se relacione diretamente".

No Projeto Estabelecimento de Nexo-Técnico - OS / INSS / n 149/93 e OS / INSS / DSS / $\mathrm{n}^{\circ}$ 251/93, essa definição de doença do trabalho é complementada por uma definição negativa dada pela Lei $n^{\circ} 6.367$, de 1976, parágrafo $4^{\circ}$, artigo 2을 retomada pela Perícia Médica do INSS com a seguinte redação: "Não pode ser considerada como doença do trabalho: a doença degenerativa; a inerente ao grupo etário; a que não produz incapacidade laborativa; a doença endêmica".

O Decreto $\mathrm{n}^{\circ} 2.172$, de 05 de março de 1997, que trata do Regulamento dos Benefícios da Previdência Social, ratifica essa definição. A Norma Técnica de Avaliação da Incapacidade, de 1997, para fins de benefícios previdenciários, utiliza a noção da doença relacionada ao trabalho incorporando os adendos anteriores. A nova redação não se refere explicitamente à "doença do trabalho"; mantém entretanto essa figura, ao referir-se aos DORT como doença relacionada ao trabalho, que seriam conceituadas pelo INSS como: "muitas doenças caracterizadas como distúrbios neurovegetativos. Doenças cujo nexo não está bem definido, aquelas não inerentes a uma ocupação, mas que acometem vários grupos de trabalhadores, mantendo sua determinação no trabalho".

Essa nova Norma Técnica vem responder à preocupação do INSS com a elevação do número de casos de LER, o aumento do número de desempregados e a redução orçamentária da Previdência Social em relação à saúde. Em conseqüência, criam-se outras diretrizes na determinação dos benefícios, abrindo outro campo de possibilidade de definição dessa doença.

Das mudanças, falam os médicos do INSS/RJ:

"Nós não estamos em hora nenhuma, pelo menos aqui na Perícia Médica, questionando se o doente ou segurado está ou não está doente".

"Nas LER, a gente levava em consideração aquela tendinite, tenossinovite, doença de Quervain, etc.; e na DORT, já fala em cervicobraquialgia, e em outras lesões do resto do sistema osteomuscular".

O propósito da Perícia Médica é definir, baseando-se em laudos diagnósticos, a concessão/negação do nexo da doença com o trabalho, e conceder o benefício que será devido ao trabalhador. Da classificação dos benefícios podem ser destacados:

- Auxílio-doença (B31) - concedido a trabalhadores doentes em caso de qualquer doença que leve à incapacidade no trabalho; 
- Auxílio-doença acidentário (B91) - concedido a trabalhadores doentes e com incapacidade para o trabalho, se, e somente, se caracterizar uma doença adquirida em conseqüência do trabalho. Será pago quando o nexo for confirmado pelo médico perito;

- Auxílio acidente (B94) - concedido como seguro mensal e vitalício, se as seqüelas das lesões decorrentes do acidente de trabalho implicarem redução da capacidade funcional.

Observamos, em nossa pesquisa no INSS/RJ, que, em relação aos DORT, a atividade da perícia fica restrita à análise da concessão/negação do benefício B31, já que a categoria de doença do trabalho é, em termos práticos, afastada. Duas tendências evidenciam-se na análise diagnóstica:

- afirmação de uma ou várias formas clínicas das LER e a negação do nexo da doença com o trabalho;

- a reconfiguração das várias formas clínicas das LER em quadros de doenças degenerativas ou reumáticas, e a negação de que o processo de adoecimento tenha nexo com o trabalho.

Nos casos de LER, o estabelecimento do B31, em detrimento do B91, representa a negação do nexo. Essa tarefa realizada pela Perícia Médica não é simples, pois vários fatores extrapolam um diagnóstico médico diferencial.

"Na perícia médica, o paciente já chega se sentindo mal e a gente tem que resolver o problema dele e não é tão simples, porque a gente não vai conceder licença a todo mundo que se acha doente. A gente tem que selecionar aquilo que é doença que gera incapacidade ou não, então gera uma relação de atrito".

O termo incapacidade, do ponto de vista do INSS/RJ, não referenda propriamente o nexo da doença com o trabalho, pois o trabalhador pode ser portador de uma doença que o deixa incapaz; ter adquirido essa doença no exercício do trabalho, mas não obter o reconhecimento da Perícia Médica de sua condição na classificação do benefício B91.

Dois casos, contados pelos próprios trabalhadores, podem exemplificar esse ponto:

“A Caixa sempre teve convênio com o INSS. Eles mandam tudo; a gente só vai para fazer a perícia. Aí, o médico do INSS - como o médico do convênio que fez a Comunicação do Acidente de Trabalho não havia colocado os três diagnósticos: tenossinovite, tendinite e síndrome do túnel do carpo, mas só a STC - ele negou o acidente de trabalho, dizendo: 'Ah! Se o médico tivesse posto na CAT os 3 laudos, eu teria dado Acidente de Trabalho’. Aí, eu 
O Território da Doença Relacionada ao Trabalho: o corpo e a medicina nas LER

perguntei: 'Mas, doutor, não tem o laudo do meu médico assistente, porque ele fez a CAT e também colocou. Não está aí com o senhor? O senhor não pode ver? Foi só um erro de transposição porque o convênio só copiou o que o meu médico que está me tratando havia colocado'. E o médico do INSS responde: 'Ah! Não, isso aí é congênito'. Aí mudou o negócio, já era congênito, que eu nasci com esse negócio no braço. Isso ah!... não dá para aceitar, não".

"Você teve problemas com o gesto profissional. Mas no meu caso foi feito tudo direitinho, não tive nenhum problema com a empresa (CEF). Mas, no entanto, o INSS também negou. Sempre arranjam um pontinho, aqui ou ali, para dizer que não pode. Quer dizer, você quer lutar pelos seus direitos e você não consegue".

Focalizando esses "pontinhos", são utilizados pela Perícia Médica "aqui e ali, para dizer que não pode" estabelecer o nexo em que mapeamos as correntes contra e a favor sobre o tema, no INSS, e as estratégias da recusa das LER. Consideramos que esse campo de descaracterização do nexo da doença com o trabalho se tornou possível dentro de definidos contextos históricos, configurados em determinados saberes sobre o corpo. Esses saberes, maximizados na relação social de trabalho, afirmam a crença do "corpo capaz para o trabalho".

Consideramos que essas estratégias e entendimentos do ato de decidir sobre o nexo estão construindo e fazendo funcionar o território da doença relacionada ao trabalho, nas LER, com suas regulagens, padronizações, continuidades e descontinuidades. A construção passa por discussões polêmicas no INSS/RJ e em outros estados, e pela busca de um difícil consenso.

\section{A Discussão das LER, INSS/RJ: Correntes Contra e a Favor}

As falas dos médicos expressam a busca desse consenso:

"Tivemos reuniões, para normalizarmos uma conduta uniforme. Recebi material sobre Norma Regulamentar e sobre DOR".

"Está havendo uma discussão ampla junto ao próprio INSS para aqueles profissionais cuja formação não é a especialidade de ortopedia, para que a gente tenha um critério coerente e um critério único. Para que a gente não venha a tomar decisões, de repente, não fundamentadas ou que, pelo menos, não venha a ter uma discussão geral ou uma orientação pela própria instituição, que é o INSS. É uma situação [a LER/DORT ser ou não doença do trabalho] que nós temos pedido, várias vezes, que haja uma diretriz". 
Marilene Affonso Romualdo Verthein - Carlos Minayo Gomez

“O que nós estamos buscando, aqui no Rio de Janeiro, é que todos tenham o mesmo entendimento, para que a Perícia Médica tenha a mesma definição. Não um posto com um trabalho e outro posto com um trabalho diferente".

Agir em nome de um discurso uníssono e legítimo não significa que exista menos polêmica nas questões das LER, entre peritos, trabalhadores, profissionais de saúde ou sindicato.

"Esses são nossa evolução e nosso sentimento, de que nós precisaríamos ter uma melhor discussão para que a gente pudesse ter as definições de critério de nexo ou não, mais homogêneas ou, pelo menos, mais bem estabelecidas. Eu acho que, em alguns momentos, essa definição está sendo personalizada ou, pelo menos, um tipo de posto, um tipo de profissional (...) acho que nós temos ainda algumas dificuldades em relação a isso. Dependendo do perito ou dependendo de quem vai dar o nexo, nós podemos ter opiniões um pouco diferentes".

As incertezas são muitas. Uns desacreditam das LER como doença do trabalho, outros acreditam, mas questionam a lesão ou a repetição como etiologia desse adoecimento. E, ainda, outros sentem dificuldade de associálas a um quadro de lesões osteomusculares já definido.

“Em alguns casos, está-se tornando bastante difícil caracterizar isso. O tempo no trabalho é um dos fatores agravantes para o desenvolvimento de uma doença profissional. Mas existem variações de pessoa para pessoa, sensibilidade maior ou menor, pessoas desenvolvem ou não alguma doença no trabalho; e têm outras que não desenvolvem. A questão da LER, eu acredito que hoje ela é questionável como uma síndrome. Algumas correntes acham que as LER não existem. Sim, você continua tendo uma tendinite, uma sinovite ou outros problemas orgânicos não dependentes efetivamente de uma atividade de esforço repetitivo".

Correntes contra e a favor configuram as análises diagnósticas das LER. Dentre as dissidências, destaca-se o trabalho da perícia do INSS de Minas Gerais. Este é acusado pelo INSS do Rio de Janeiro de ser "mais abrangente no entendimento da doença do trabalho", por ter concedido um número maior de benefícios acidentários para os trabalhadores com LER. Essa diferença de encaminhamento tem sofrido pressões e capturas em âmbito nacional.

"Aconteceu um congresso, se não me falha a memória, ano passado, com o grupo mineiro, com o grupo do Brasil todo. Mas para poder avaliar o que 
é que MG estava fazendo, o que é que MG estava entendendo por isso (...) e parece que estava havendo, não digo benevolência, mas um entendimento mais abrangente do que é uma doença profissional ou não. Estão revendo os conceitos para que a gente tenha um entendimento em nível nacional único, para que a gente não tenha um estado com um entendimento diferente, facilitando ou, de repente, agindo diferente dos outros estados da União".

Se não pretendemos generalizar a idéia de que todo trabalho prescrito é lesivo para a saúde e que a saúde é uma prescrição de produtividade ininterrupta, acreditamos menos ainda que possa ser generalizada a lógica de entendimento onde a doença se mede pelo grau de incapacidade, via análise da inutilidade, dos constrangimentos e da impotência do corpo, reafirmando a inexistência do nexo entre a doença e o trabalho.

"Existia uma equipe de profissionais mexendo na área do trabalho, única e exclusivamente, para caracterizar as lesões por esforços repetitivos, se eram ou não causadas pelo trabalho. Certo? Estatisticamente, em Minas Gerais, deu uma guinada. Havia uma maior tendência a dizer que era uma doença profissional e isto está sendo discutido".

Essa busca constante de um consenso para as LER, na negativa do seu nexo com o trabalho, tem como recurso o desenvolvimento de algumas estratégias de recusas específicas que podem ser observadas na atividade da perícia médica do INSS/RJ.

\section{Estratégias para a Recusa do Nexo}

Podemos observar que várias estratégias são articuladas com o objetivo de dissociar corpo-doente e trabalho, via concessão/negação do nexo. $O$ depoimento de um profissional do Núcleo de Saúde do Trabalhador, da Secretaria Municipal de Saúde do Rio de Janeiro, ilustra bem o modo como a questão financeira atravessa essa discussão:

"O INSS dificulta o diagnóstico. Eu acho que essa dificuldade de diagnóstico está relacionada com o fato de o INSS hoje estar querendo privatizar essa parte do seguro acidente. Aí, quanto maior dificuldade você tiver em fazer o diagnóstico, melhor, porque o seguro não quer pagar. $\mathrm{O}$ seguro tem que dar lucro e quanto mais você botar o pessoal de fora, se você não faz o diagnóstico na época, você não entra no INSS, então a estatística cai. Cai o número de beneficiados (...) - parece até que isso é um grande benefício; esse nome é horroroso; isso não é benefício nenhum". 
O fator financeiro legitima o auxílio-doença não como um direito, mas como um prejuízo a ser controlado e administrado. Neste caso, o recebimento do benefício atende a uma expectativa de resguardar o trabalho como um valor moral, devido por aquele que atende ao bem-estar social geral da população. Mas poderíamos questionar: quem merece o benefício? Por que adoecer desmoraliza o trabalhador? Que relações de força levam o trabalhador a continuar no trabalho, mesmo doente, negando a vida em prol de um lugar na sociedade ativa? Como são negociados lucros e prejuízos na distribuição do benefício previdenciário?

O prejuízo está relacionado com o tipo de beneficio concedido, assim diz um médico:

“(...) se você caracterizar, hoje, o que é uma doença profissional, o segurado teria direito a um auxílio, ou, pelo menos, a uma situação próxima a $100 \%$ dos vencimentos dele. Quando você caracteriza um auxílio-doença, você tem o cálculo, hoje, baseado nas últimas 12 ou 36 contribuições. O que acontece? Você teria uma remuneração menor, respectivamente. Então, esse é um ponto que também precisa ficar bem caracterizado, para que o trabalhador não venha a ter prejuízo financeiro ou econômico".

Alguns documentos são analisados para justificar a recusa do nexo, uma vez que o processo de encaminhamento pode evitar prejuízos financeiros e concretizar tecnicamente essa recusa. Entre eles são destacados: os diagnósticos do serviço médico da empresa ou de médicos conveniados; as descrições das atividades do trabalhador, formalmente encaminhadas pela empresa, e a denominação da categoria funcional do trabalhador. Mas é a Norma Técnica para Avaliação da Incapacidade, de 1993, revisada em 1997, que irá normatizar a negação do nexo, ao tratar do indeferimento do auxílio-doença acidentário em duas situações específicas:

- por inexistência de incapacidade, com parecer da Perícia, fundamentando tecnicamente a recusa. Neste caso, não se configuraria a doença para fins de benefícios pecuniários;

- com assegurada incapacidade, porém sem nexo caracterizado.

Na prática, argumentando que a empresa negligencia sua responsabilidade em relação à saúde do trabalhador, e que o empregado espera receber benefícios que nem sempre merece, o médico perito nega o benefício:

“A empresa não liga para a saúde do trabalhador, liga para a saúde do bolso do trabalhador e agora então, com o desemprego em massa, isso aqui enche. 
O Território da Doença Relacionada ao Trabalho: o corpo e a medicina nas LER

Porque o trabalhador está perdendo emprego, ele vai para o INSS. Já que ele pagou, tem na idéia dele que ele descontou a vida inteira, então agora ele tem que ser ressarcido. Não é isso. Um problema social enorme, uma entrada de requerimento de benefício enorme, o nosso trabalho aumenta, a gente tem que começar a negar mais".

"O INSS, na realidade, é uma grande seguradora".

"Não vai conceder licença a todo mundo que se acha doente".

Para "negar mais", o médico perito agiliza outras estratégias. Por exemplo, nega o nexo quando avalia pedidos de trabalhadores que não são formalmente registrados como digitadores, embora utilizem, ininterruptamente, o terminal de vídeo. Esse hábito se baseia na antiga regulamentação da Portaria do Ministério da Previdência Social n ${ }^{\circ}$ 4.062, de 1987, que diagnosticava como tenossinovite por esforços e movimentos repetitivos somente quando estes eram provenientes da função de digitadores. Em 1991, a legislação foi ampliada pelo Decreto $n^{\circ} 375 / 91$, quando o conjunto das Lesões por Esforços Repetitivos foi reconhecido como doença do trabalho. Admitiu-se que o avanço da tecnologia e da computação estendeu o exercício da digitação a várias outras funções que tratavam, armazenavam e informavam dados por meio do computador. E, desta forma, outras funções que apresentavam tarefas repetitivas foram também indicadas na categoria de risco. Porém, o ato da perícia médica considera a digitação, formalizada no papel profissional, como código-chave para análise da existência do nexo, desconsiderando a ampliação da lei.

Outra estratégia da negação do nexo se faz pela interpretação e uso particular da Norma Regulamentar $n^{0} 17$. A Delegacia Regional do Trabalho reeditou, em 1990, a NR-17, pela Portaria $n^{\circ} 3.751$, referente aos aspectos ergonômicos do uso específico de terminais de vídeo, regulamentando cota de produção e pausas, posto de trabalho e equipamentos. Essas prescrições, que a princípio serviriam para normatizar a otimização das condições de trabalho em relação às condições físicas e mentais dos trabalhadores, são codificadas como dados em si, de garantia inquestionável de um trabalho não repetitivo e com paradas apropriadas para o descanso.

Duas análises configuram essa linha de pensamento: 1) a empresa cumpre as exigências da NR-17, o trabalhador adoece, mas o nexo não é afirmado porque o trabalho executado dentro do prescrito pela lei não faz adoecer. Desta forma, se as exigências de um trabalho asséptico foram estabelecidas e o processo de adoecimento acomete o corpo do trabalhador, 
o problema é desse corpo; 2) a empresa não cumpre a norma e o trabalho é executado fora dos padrões de segurança; o trabalhador adoece e o nexo também é negado, porque, para o perito, houve negligência em relação às possibilidades de adoecimento. Como a negligência é da empresa, o adoecer não caracteriza laços necessários com a atividade do trabalho em si, mas com a segurança de um trabalho que é sucateado pela empresa e que acomete um corpo desavisado e, sendo assim, concluem, não há como onerar o INSS.

Entre a exigência da lei e a negligência da empresa, o trabalhador é o "segurado". Mas, por outro lado, o "segurado" desaparece na "(im)previdência social" (Oliveira e Teixeira, 1989), que não quer correr o risco do ônus de um processo de adoecimento. Essa discussão pode entrelaçar várias questões, onde a noção de capacidade para o trabalho está associada, historicamente, a uma assepsia não só dos locais de trabalho, mas do corpo no trabalho. Algumas dessas noções podem ser questionadas: que concepção de doença permite a negação do nexo em quase todos os casos de LER e como o fato de tornar-se incapaz, em nenhum momento, assegura a esses trabalhadores a concessão do auxílio-doença acidentário? Que estratégias de saber/poder funcionam para que os diferentes tipos diagnósticos das LER, mesmo se confirmados, possam ser classificados pelo INSS como "doença comum", isto é, passível de acometer a população em geral e, conseqüentemente, sem relação com as condições de trabalho de quem adoeceu?

Para os peritos, é necessário evitar que a concessão do auxílio-doença acidentário seja manipulada para ganhos secundários dos trabalhadores em período de crise econômica e social, caracterizando a avaliação médica da capacidade laborativa de modo peculiar. Diz o médico:

"O que nós temos que deixar bastante claro é que a perícia médica é uma avaliação médica e de capacidade laborativa, e não uma situação social, onde várias instituições que estão sendo privatizadas (ex. Banerj, BB e outros) (...) venham buscar o profissional da perícia como uma forma de segurança para o seu futuro".

Não há ênfase no diagnóstico da doença, mas na avaliação do grau de incapacidade do segurado:

“A perícia é uma forma técnica de liberar benefício por doença, doença grave. E para a caracterização crítica, digamos assim, na avaliação do grau de doença, do quanto isso é incapacitante para o segurado, ele tem que fazer uma perícia (...) não faz diagnóstico, não faz tratamento, a gente só avalia o grau de 
O Território da Doença Relacionada ao Trabalho: o corpo e a medicina nas LER

incapacidade do segurado. Quanto tempo provavelmente terá esta incapaci-

dade e qual o grau. Se ela permite retornar à atividade laborativa ou não”.

O grau de incapacidade do segurado, ao servir de parâmetro para o diagnóstico de uma doença do trabalho, torna necessária a associação dicotomizada entre trabalho/saúde e corpo incapaz/doença. Essa doença tida como incapacidade, que nos parece tão conhecida, não é natural. Foram contextos históricos definidos e interesses sociais delimitados que a inventaram.

\section{A Doença como Inutilidade}

A possibilidade de a doença ser inscrita no registro do inútil surge, no século XVIII, com a emergência do corpo como foco do bem e do mal. Nessa época, há um deslocamento importante do olhar médico sobre o corpo, que comporá dois movimentos: de um lado, o corpo como objeto de conhecimento e; de outro, uma linguagem que fala desse conhecimento sobre o ser, a partir de uma nosografia política aderente ao contexto social da época.

Vemos emergir então, no século XVIII, o que será ratificado nos séculos seguintes: a associação entre saúde/trabalho e corpo/doença. E, com a consolidação do capitalismo, afirma-se a vinculação que vivenciamos, hoje, entre saúde e capacidade para o trabalho. Segundo Herzlich (1986, p. 206), essa associação não correspondeu a um processo natural, mas a um processo sócio-histórico que fez emergir no campo da medicina uma nova conceituação de saúde, onde seu avesso, a doença, tornou-se "uma condição socialmente reconhecida e legítima de inatividade". Assim, a partir dessa data, criou-se a necessidade de um cuidado médico para restaurar o corpotrabalho, atendendo ao processo produtivo. Essa condição de inatividade, posteriormente, será reconhecida pelo médico do trabalho, para exercer a função de detectar, diagnosticar e barrar o corpo doente dos trabalhadores. Tal procedimento não aconteceria de forma pacífica. Vários movimentos operários surgiram, reivindicando melhor qualidade de vida, já deixando claro que a percepção de saúde, medida pela dicotomia doente/não-doente, não era tão hegemônica, mesmo que resoluções excludentes e mercenárias fossem, ao longo dos anos, empreendidas.

São exemplos de resoluções excludentes e mercenárias: as demissões de trabalhadores após o diagnóstico de uma doença; a negação freqüente do nexo da doença com o trabalho; a atitude do médico de não registrar o diagnóstico da doença, para não onerar nem a empresa como responsável nem o INSS como seguradora. 
Há, na perspectiva da Perícia, uma volatilização das LER enquanto doença do trabalho. Conforme a afirmação de um médico: "LER é um termo em desuso. Está começando a ser provado que as dores e lombalgias, que as pessoas alegam, não são LER. Mudou para DORT. Na CAT, deve ser LER/DORT". Mudanças que não passam despercebidas aos olhares ao redor, diz uma funcionária do INSS:

“A função da Perícia Médica era essa, homologar processos de B31 para B91; que agora acabou, porque saiu uma nova Lei do Ministério da Previdência (...). Faz perícia de B31 todos os dias. De B91 e de LER, é que, até o presente, não faz mais, não. Os casos de LER estão todos parados".

$\mathrm{O}$ encaminhamento do nexo em relação às LER torna-se um recurso cada vez mais sofisticado ao servir para negá-las como doenças do trabalho, pois além de apagar suas inscrições e histórias anteriores, vai construir um espaço de subjetividade para o trabalhador, ao circunscrevê-lo em um perfil: é estável e não-doente o corpo que continua a trabalhar, mesmo com as restrições. O DORT é diagnosticado na Perícia Médica.

\footnotetext{
“(Mas) a pessoa não tem atrofia nos membros superiores ou nos membros inferiores - que pode dar em qualquer segmento; não tem bloqueio articular, não tem diminuição da força, tá (...) não tem, digamos assim, edema ou inflamação visível, então ela pode manter a atividade laborativa, claro, com alguma restrição - pequena restrição porque ela não tem alteração que a impeça de trabalhar. Então, é o mesmo esquema: pode ter o diagnóstico de DORT, digamos assim, porém a pessoa está estável”.
}

Nesse caso, para a Perícia, há ligação entre corpo e trabalho se "a pessoa está estável" e é capaz, mesmo com o diagnóstico de DORT. Por outro lado, se as alterações o impedem de trabalhar, não há nexo, porque o corpo, agora inútil, não compõe com o trabalho, mas com o sujeito que adoece. Desta forma, forja-se a falsa distinção entre doentes e doenças, separando o corpo que adoece do sentimento sobre o seu estado. Teríamos, nessas dicotomias, doenças sem doentes (incapazes que se sentem capazes) e doentes sem doença (capazes que se sentem incapazes). Essa articulação compõe uma lógica de capitalização da saúde, onde não há trabalhadores doentes, mas sujeitos que adoecem, tomados genericamente, pelo INSS, na classificação de segurados. Traça-se assim uma metodologia de ação racional e científica que pensa o trabalho não afetando o corpo, e pressupõe a saúde como ausência de doença ou disposição para o trabalho. 
A saúde, na dimensão do corpo, capaz para o trabalho ou na compreensão de um corpo-instrumento, atualiza o território do ideal-de-trabalhador e, principalmente, ratifica um perfil de ser específico para a produção - estável, previsível, ordenado e submisso às leis da produtividade a qualquer preço.

Insistimos. Não falamos de todo o trabalho nem de qualquer saúde no trabalho, mas de uma racionalidade no agir sobre o corpo, que toma antigas formas de prescrição médica para normatizar regimes e condutas para a vida diária. A medicina, desde a época clássica,

(...) não era simplesmente concebida como uma técnica de intervenção que, em caso de doença, empregaria remédios e operações. Ela também devia, sob a forma de um corpus de saber e de regras, definir uma maneira de viver, um modo de relação refletida consigo, com o próprio corpo, com o alimento, com a vigília e com o sono, com as diferentes atividades e com o meio. (Foucault, 1985, p. 106)

Uma intervenção médica, que funcionando para conduzir a autogerência vigiada dos corpos, passa a partir do século XIX a referenciar um corpo capaz para o trabalho e a imputar ao sujeito a responsabilidade do adoecer. Essa razão médica fixa no corpo o ônus pelo descuido de adoecer. A pesquisa de Luz (1996) também mostrou que os doentes são discriminados, moralmente, a partir da idéia de um corpo descuidado que se torna enfermo pelos próprios excessos.

Nessa associação dicotômica - de um lado, o trabalho e a saúde e; de outro, o corpo e a doença - vemos emergir um saber, objetivando um poder (descarte do corpo-doente) pela produção de um corpo portador do mal (incapaz). São corpos produzidos por formações sociais, onde, segundo Foucault (1968), um exercício de poder micropolítico, difuso e não localizado, passa a ser estratificado por um saber e legitimado pela sociedade, à medida que se repete como logos no campo da saúde e da doença.

Esse campo de pensamento, ações e sentimentos sobre a saúde individual ou populacional não se configura apenas pelo saber/poder médico, mas também, segundo Sontag, por representação social. A autora, estudando a doença como metáfora, afirma:

Toda sociedade, ao que parece, precisa identificar uma determinada doença, com o próprio mal, uma doença que torne culpadas suas vítimas (...) deixar de considerar a doença como um castigo adequado ao caráter moral objetivo, 
Marilene Affonso Romualdo Verthein - Carlos Minayo Gomez

dela fazendo uma expressão de individualidade interior, poderia parecer menos moralista. Mas esses pontos de vista acabam por ser tanto ou mais moralistas ou punitivos (...) a idéia romântica de que a enfermidade exprime o caráter é invariavelmente ampliada para afirmar que o caráter é a causa da doença. (1984, p. 60-61)

Se atentarmos para o fato de as LER serem doenças associadas a um perfil de morbidade, onde o indivíduo é descrito como obsessivo, minucioso e detalhista em seu comportamento frente ao trabalho, inferimos que as descrições dessa doença, no campo moral, individualista e metafórico, vão construir formas de subjetivação específicas. Podemos retomar nosso tema do silêncio do corpo-doente no trabalho quando constatamos, pelos matizes que são dados historicamente ao conceito de corpo, uma pré-conceituação de caráter mórbido.

Neste caso, a produção de uma personalidade mórbida ou, como nos falam os médicos do INSS, de uma "pessoa predisposta ao adoecimento", irá identificar o doente na sociedade, mas não o doente do trabalho. Um laudo do INSS/RJ exemplifica a idéia.

"A segurada é portadora de cervicobraquialgia difusa, osteoartrose difusa, cervical lombar crônica, doença degenerativa com o comprometimento cérvico braquial, não caracterizando a doença profissional. Nega B91".

A negação de doença do trabalho tem repercussões sociais na vida de quem adoece. Segundo Herzlich (1986, p. 203), é a perda de um código identitário, pois na doença profissional o indivíduo conserva sua identidade: a doença corresponde, para ele, a uma integração social específica mais persistente; o papel de doente é um papel social".

Para a autora, a pessoa doente procura uma identidade social para sintomas e disfunções, que somente tomam sentido e se organizam em doença à medida que introduzem uma modificação na vida do doente e, conseqüentemente, nessa identidade. Tais critérios definem as relações de maior e menor gravidade da doença. Concordamos quando a autora afirma que o papel de doente do trabalho assegura uma "integração social específica". Mas qual a sua especificidade? Que códigos sociais de saúde, trabalho, corpo e doença são articulados em um papel que identifique o doente e o não-doente, o doente do trabalho ou outro?

É importante observarmos que a incorporação de papéis identificatórios - produtivo, improdutivo, saudável, doente - imprime esquadrinhamentos de 
saber/poder sobre o corpo. São efeitos de poder frente a saberes que fixam como deve ser e se comportar um corpo, quer seja ele saudável, trabalhador ou doente para a sociedade. Efeitos de poder sobre o corpo que, no desvio da normalidade, deve ser, como no caso das LER, reparado, ajustado, adaptado e treinado para o trabalho produtivo, ou isolado, quando fixado em uma predisposição mórbida.

A identificação da doença, no registro da predisposição, referendada pelo INSS/RJ, tem atribuído ao doente o papel de incapaz, tomando como parâmetro de saúde a capacidade para o trabalho. Daí talvez o relato de muitos pacientes sobre o desejo de voltar à identidade social perdida, no caminho desviante do seu processo de adoecimento: "quero voltar a ser a trabalhadora que eu era antes de ficar assim...". A doença, como inutilidade, toma o papel do avesso, do reverso e até, no limite, da morte social.

A morte social expressa, no caso dos pacientes com LER, esse sentimento de perda de identidade. Espelha, como sublinha Ribeiro (1997), a estranheza dos trabalhadores em relação a eles mesmos, ao não se sentirem capazes de trabalhar e cuidar de si e dos outros, culpando-se por isso; dos colegas de trabalho, que os percebem trabalhando pouco ou mal e o acusam e, ainda, a dubiedade médica em relação a sua doença.

Em sua pesquisa sobre a atividade dos bancários em São Paulo, Ribeiro observa que as análises pelo viés da predisposição tentam explicar a prevalência do gênero feminino nas LER, mas "podem alimentar preconceitos e discriminações e culpar os adoecidos dos dois gêneros por seu próprio adoecimento" (1997, p. 195). Naturalizando-se as exigências do trabalho, continua, operar-se uma inversão quando "a sujeição dos que trabalham ameaçados de adoecer se converte em fator individual de risco para a produção" (Idem, p. 196).

Neste contexto, o processo de adoecimento revela sua condição histórica e social de violência pela submissão, mesmo que formas mais sutis de exigência de trabalho estejam sendo desenvolvidas. Pondera o autor que há, na atualidade, uma modificação na apropriação do corpo, mas ainda assim a submissão é intensa e contínua, posto que os espaços de mobilidade são estreitos e rígidos.

O corpo continua sendo exigido, mas de outro modo. Os esforços são agora bem mais leves, mas contínuos, rápidos, dando a impressão de inocuidade, tal a leveza no manuseio das máquinas industriais e de escritório. E quando se requer mais destreza, exige-se mais atenção. O corpo, agora, sai pouco do 
Marilene Affonso Romualdo Verthein - Carlos Minayo Gomez

lugar. Nesses trabalhos atentos, tensos e intensos, a cabeça e os olhos seguem os passos rápidos da produção, as mãos se movimentam, mais que o resto do corpo, e os braços as acompanham ou se deslocam em posturas mais ou menos rígidas para que elas executem as tarefas prescritas. (Ribeiro, 1997, p. 186).

Neste caso, argumenta, opondo-se a essa idéia da predisposição nas LER, que a impropriedade nos casos de adoecimento não está na pessoa, nem no gênero, mas nas complexas condições de subordinação e hierarquização que são desenvolvidas no trabalho.

\section{Do Corpo Devoto ao Corpo-útil}

Há muito tempo, as tarefas quotidianas respondem à exigência do controle dos próprios desejos. Na Grécia, essa contenção denominava-se temperança, na qual o equilíbrio das forças internas e externas dava a medida do domínio e da liberdade do próprio corpo desejante e produtivo. Na Idade Média, o desejo era contido para ser reconstruído pelos desígnios de Deus. Apostando na mortificação da carne para o enriquecimento espiritual, o programa de vida ascética dos monges prescrevia "tarefas repugnantes para evitar ao máximo os sonhos e a moleza do repouso" (Gondar, 1990, p. 27).

A eliminação do desejo acontecia pela manutenção do corpo em atividades sistemáticas e exaustivas. Assim, no mosteiro, "trabalho como um todo passa a sofrer uma série de marcações abstratas que regulam as atividades por intervalos de tempo, intercalando-se em tempo para a meditação, para as orações em conjunto e para o trabalho" (Idem, p. 27). Aqui a colagem entre corpo e trabalho é uma obrigação moral. O corpo exausto eleva a própria alma. Se naquele momento a associação servia à purificação da alma, ela atravessará os séculos servindo ao que será, no século XVII, invocado como dignidade humana.

No século XVII, novos olhares sobre o corpo serão proporcionados pelos estudos de Descartes, na Filosofia; e de Newton, na Física: Descartes, associando o corpo à idéia mecanicista de homem-máquina; e Newton ${ }^{3}$, privilegiando a ordem, a estabilidade e a certeza do mundo, que abarcaria a previsibilidade da conduta humana.

É bom ressaltarmos que esse homem-máquina será associado ao traba1ho, não só por um sentido moral, como já vimos, mas também, conforme observa Weber (1985), por um "espírito do capitalismo", isto é, por uma base "ética ascética do trabalho", na qual a ação é orientada para determinados 
fins em função de alguns valores. Desta forma, a ética é compreendida como uma racionalidade de agir e pensar em busca de lucro que articula um ethos específico.

Assim, o trabalho deixa de ser uma tarefa executada pelo corpo para purificar a alma, e passa a ser um mecanismo estratégico ancorado dentro de um projeto ético e construído com base na Reforma de Lutero, segundo a qual a idéia de evocar a ação propunha o cumprimento das tarefas como caminho para servir a Deus. O sujeito endividado para com Deus prestaria contas através do trabalho. Logo, cada cidadão, na sua interioridade, na sua condição de falta para com o Senhor, teria uma divida a pagar trabalhando. No protestantismo de Calvino, a vocação de um homem eleito para a glória de Deus pode ser entendida como um dever-ação ou devoção, onde as tarefas servindo à vontade de Deus "assim na terra como no céu", racionalmente organizadas, poderiam prover "o pão nosso de cada dia" e articular o trabalho como uma providência divina.

Segundo Weber, a idéia traz um projeto ético de subjetividade para o qual “(...) não somente é absolutamente indispensável um desenvolvido senso de responsabilidade", mas também um senso de dever e vocação para o trabalho: um sujeito que ao se associar ao trabalho devoto tem como subsídio "um longo e árduo processo de educação" (1985, p. 39).

Pode-se talvez considerar que esse "árduo processo de educação" permitiu a passagem do corpo-devoção para o corpo-útil, isto é, o corpo capaz para o trabalho. Pode-se ainda questionar de que maneira esses laços entre subjetividade e trabalho nos ajudariam a problematizar a noção de "capacidade para o trabalho" tão premente nas atividades da Perícia Médica do INSS/RJ que ora estamos analisando.

Essa capacidade não pressupõe uma natureza, mas um corpo disciplinado e controlado pelo exercício. Não um exercício qualquer, mas um exercício de poder sobre os corpos, para moldá-los em corpo-útil e dócil para o trabalho. Essa tese foi defendida por Foucault, ao estudar - retratando a disciplina imposta aos corpos no final do século XVIII e início do XIX - uma anatomia política. Uma mecânica de poder que, segundo o autor:

Define como se pode ter domínio sobre o corpo dos outros, não simplesmente para que se faça o que se quer, mas para que se opere como se quer, com as técnicas, segundo a rapidez e a eficácia que se determina. A disciplina fabrica assim corpos submissos e exercitados, corpos dóceis. (Foucault, 1977, p. 127) 
Entendemos que, desta forma, uma anatomia de corpo-útil (capaz) e dócil para o trabalho articulava uma economia de subjetividade necessária à época.

Verificamos, a partir das atividades do médico perito do INSS, que a idéia de um corpo capaz vai dimensionar, além da utilidade, a noção de vida saudável. Neste caso, a aliança da saúde com a capacidade para o trabalho faz da medicina um instrumento de intervenção política por excelência. Se, no século XIX, a medicina e, mais especificamente, a terapia psiquiátrica, julga como perigosos os comportamentos não incorporados à conduta regular e normal; no século XX, a medicina tomará o trabalho como referência para julgar o que considera normal ou anormal na sociedade, posto que

(...) o trabalho não é mais apenas uma técnica terapêutica, mas constitui um fator fundamental para discernir entre indivíduo normal, socializado - que produz - e o anormal, degenerado - improdutivo. (Portocarrero, 1990, p. $5)$.

A doença como inutilidade permite alguns registros sobre o corpo. Já vimos a produção de um corpo assujeitado e sem resistência, no qual a dor e o sofrimento são sinais de degenerescência e/ou de fragilidade constitucional. Outro registro, como veremos, é o do sentido dado ao corpo-simulado: o corpo que se seduz pelo avesso do que é regrado como conduta normal e se apresenta fingindo-se de doente para não trabalhar. Esse corpo, também regido pela idéia de inutilidade, expressa a cópia desajustada e deslocada do referencial de saúde como matriz da capacidade no trabalho.

O registro, no INSS/RJ, desse corpo simulado passa pela controvérsia existente entre os sinais dos exames clínicos e dos exames de imagem. A transparência proporcionada pela imagem do corpo proporciona um novo caminho no processo de subjetivação desse corpo, no âmbito da doença relacionada ao trabalho. Neste caso, precisamos também entender de que forma a doença aparece na transparência do corpo-simulado.

\section{A Transparência do Corpo-simulado}

O trabalho De morbis artificum diatriba, de Ramazzini, em 1700, descrevia a doença dos escribas, que ficou posteriormente conhecida como cãibra dos escrivães, através da observação médica do uso do corpo dos trabalhadores - no caso, da musculatura exigida para o ato da escrita. Esse médico relata que posições forçadas e inadequadas do corpo vão produzindo, com o tempo, enfermidades corporais. Sendo assim, relata que a doença 
dos escribas advém da sensação de peso e dores nas mãos, braços e ombros, pela concentração e tensão muscular estática, esforço repetitivo e sedentarismo.

Desse primeiro registro às polêmicas leituras atuais da linguagem do corpo nas LER, podemos notar dados de continuidade, quando os médicos atribuem a dor e ao sofrimento à hipersolicitação osteomuscular e posturas inadequadas, mas também de descontinuidade, ao codificarem hoje o processo de adoecimento com elementos orgânicos e de personalidade do trabalhador que, simulando dores - como dizem os peritos -, pretendem ganhos secundários. Essas leituras do corpo nos introduzem nos referenciais de verdadeiro e falso da dor.

Pode-se dizer que, ao instituir sistemas de sinais, codificar e decodificar padrões de normalidade por critérios de falso e verdadeiro no registro da confissão da dor, o médico perito do INSS/RJ aborda categorias definidoras das LER, induzindo a crença de um falso juízo da própria dor, ou da própria doença. Assim, reinscreve-se, na Perícia Médica, a sigla LER como "Lorota dos Espertos Remunerados".

A idéia de um corpo que simula a própria dor interfere nas relações cotidianas dos trabalhadores com médicos, familiares e colegas de trabalho. Queixam-se os doentes: "o pessoal acha que estamos tentando enganar, que estamos mentindo (...)"; ou ainda, "alguns acreditam que me finjo de doente para não trabalhar".

Essa noção coloca o trabalhador que adoece numa possibilidade de decodificação potencial, onde o que realmente importa não é a idéia que o médico tem a respeito do que escuta ou vê no exame clínico, mas da imagem que obtém, por uma tecnologia sofisticada - eletromiografia, radiografia, cintilografia, ultrassonografia, ressonância magnética - das queixas, dores e sofrimentos desses trabalhadores. Os médicos fazem a leitura do corpo a partir da transparência dele, ou seja, interpretam seus sentidos pelas imagens que representam os fatores de adoecimento.

É a criação de uma medicina preventiva, que utiliza em grande escala uma tecnologia sofisticada, colocando a idéia dos exames complementares como o ser sensivel, capaz de informar sobre a iminência de uma doença que acomete um ser, que ignora o próprio sentir. Nesse percurso, a história dos males é revista na racionalidade médica atual: "torna-se uma história médica e mesmo uma história tecnológica dos males" (Witkowski, 1997, p. 432).

A tomada do corpo pela sua transparência fica ancorada na relação entre a medicina e a tecnologia. O corpo, no cenário contemporâneo, é o centro 
da pesquisa tecnológica das sensações. Como coloca Bruno, entram em relação, na interação corpo-imagem, sensores, sons, imagens, câmeras, reconfigurando tanto o espaço interno do corpo quanto sua exterioridade, em sua "capacidade de expressão, afecção e conexão, para além da pele e dos limites territoriais naturais ou etológicos" (Bruno, 1999, p. 99).

A observação, pelos aparelhos, da mobilidade dos fluxos do corpo através da imagem interior do corpo, não apenas transforma a anátomo-fisiologia, mas, mais ainda, afeta a sensibilidade do observador e sua relação com a medicina. Introduz-se outro habitar corpóreo na relação interior/exterior. $\mathrm{O}$ corpo, como imagem para o observador dos exames gráficos, é um corpo de identidade continuamente modulada, mas pode apresentar, no registro médico, estatísticas fixas que codificam o saber/poder da normalidade.

Talvez o médico perito, ao lançar mão da tecnologia como padrão para conceder/negar o nexo, utilize a técnica para afastar, no processo médicopaciente, o que expressa o próprio sentir do corpo: pulsar, esquentar, gelar, endurecer, fraquejar.

Na Norma de 1997, há um alerta ao uso abusivo dos exames imagéticos. Diz o texto que, embora a parestesia possa indicar o uso de eletromiografia para o diagnóstico diferencial, esse procedimento "tem alto custo, é invasivo e sem resposta conclusiva adequada para DORT".

A mesma Norma de 1997 postula que os diagnósticos dos DORT são "eminentemente clínicos", colocando a caracterização da dor como elemento imprescindível na sua avaliação diagnóstica e que, na análise comparativa entre os dois exames, "são minoria os casos em que os exames complementares apóiam o diagnóstico clínico".

A afirmação da dor nas LER pode ser acompanhada nesse mesmo documento. A dor muito nos informa, de maneira geral, sobre o processo de um adoecimento. Pode ser, geralmente, insidiosa e pouco definida, mas também pode traduzir o comprometimento de um músculo, tendão ou nervo específico. A dor, como sintoma de doenças inflamatórias, pode indicar comprometimento das bainhas, das tendíneas e dos tendões, por grande repetitividade e exigência de força e, nesse caso, auxiliar na caracterização das tendinites, das tenossinovites e das epicondilites.

Não só a dor, mas também outros elementos expressos pelos pacientes são indícios para o diagnóstico clínico, como por exemplo as alterações de sensibilidade. Por esses sinais podem ser detectadas as neuropatias compressivas - entre as mais conhecidas, a síndrome do túnel do carpo e a lesão do nervo mediano. 
A disparidade entre o exame clínico e os exames de imagem nos faz rever o deslocamento da postura do médico em relação ao ato diagnóstico, já enunciado pelo estudo de Foucault em Nascimento da clínica. Esse estudo esclarece que a clínica como fato histórico produziu uma mutação no saber médico quanto ao entendimento do espaço corporal, redefinindo a compreensão do patológico e a articulação da doença com o corpo doente. O fato veio caracterizar o território da medicina moderna, ao trazer a idéia de um corpo que adoece, deixando para trás a idéia de doença como resultado de possessão demoníaca, ou castigo de Deus. O corpo humano, em sua geografia anatômica, passa a constituir o espaço sólido e visível da doença e fundamento para o discurso médico. Hoje, com as tecnologias das imagens, o espaço do corpo torna-se transparente e esse poder de visibilidade sobre ele é ampliado em dimensões inimagináveis naquela época.

Os médicos peritos, a partir da tecnologia de imagens, produzem não só referenciais de afirmação/negação do nexo em relação às LER, mas, principalmente, inventam mundos possíveis para a relação entre saúde e doença, assim como para a leitura dos corpos inscritos por ela. Corpos como imagens fugazes de trabalhadores temporários, domiciliares, avulsos, ou que trabalham (e que adoecem) por conta própria. Segundo os laudos médicos de negação do nexo, não são detectadas nos exames as imagens que possam materializar a dor e as queixas, esvanecendo, dessa forma, a possibilidade da doença do trabalho. Assim, de novo nos deparamos com a perplexidade do silêncio da doença do trabalho a que nos referimos no início do texto, e da igual volatilização da imagem do sujeito caracterizado como segurado.

Quem é o segurado acidentário para o médico do INSS? Não é o trabalhador que adoece, uma vez que a doença é diagnosticada e registrada nos laudos de requisição de nexo, que, na maioria das vezes, é negado. Também não é o trabalhador que fica incapaz de trabalhar, posto que a emergência da incapacidade não é associada à história de quem trabalha e adoece. Não são os trabalhadores que, por muitos anos, digitam e mostram marcas de enfermidade no corpo, pois não são reconhecidos como portadores de doença do trabalho.

Neste sentido, são ilustrativos os depoimentos de duas trabalhadoras.

"Tenho 18 anos como digitadora, estou com isso há três anos, eu acho que é acidente de trabalho, porque eu adquiri isso porque estava trabalhando, não adquiri isso brincando, nem dentro de casa. Mas o INSS não reconhece, o 
Marilene Affonso Romualdo Verthein - Carlos Minayo Gomez

processo está rolando há anos. Já estive no Centro de Reabilitação Profissional, mas só pude ficar quatro meses porque estava cadastrada como auxílio-doença".

"O INSS negou o B91 dizendo que a doença era congênita. Tive diagnóstico de síndrome do túnel do carpo, tendinite e tenossinovite e ele disse que era doença congênita de nascença, que eu já tinha isso antes e não é verdade. Sempre fui uma pessoa saudável e nunca tive problemas com o meu braço”.

Que limite de incapacidade necessitará mostrar o corpo para provar que está verdadeiramente doente e, principalmente, como associar ao processo de adoecimento a sua história de vida e trabalho? Qual a possibilidade de resistência do corpo no silenciar da doença do trabalho?

\section{A Doença como Resistência do Corpo aos seus Constrangimentos}

O estudo de Borges (1999) com trabalhadores bancários com LER mostranos uma representação, bastante enfática, do imobilismo associado a questões institucionais ou pessoais que podem nos ajudar a pensar sobre a produção do silêncio do corpo no território da doença relacionada ao trabalho. Diz o autor:

Numa sessão de sociopsicodrama realizada com um grupo de doentes de LER, houve a construção coletiva de uma imagem simbólica onde o trabalhador era impedido de andar para a frente por inúmeras forças que se localizavam em todas as partes de seu corpo, grudadas nele, imobilizandoo (...) a doença imobiliza pela dor. Grande parte das relações interpessoais mediadas pelas instituições e organizações de produção e trabalho imobilizam pela exclusão. (Borges, 1999, p. 5-6)

Entendemos que essa imobilização do corpo necessita de estratégias de saber e poder que agem sobre ele, produzindo silêncio e que, além disso, não ocorrem só no espaço do corpo, mas são articuladas com investimentos sociais e institucionais nas linhas de concepção do trabalho, da saúde, da doença, dos colegas de trabalho, das chefias e das famílias.

Mas quais seriam as forças de produção desse silêncio do corpo?

- Aglomerado de hábitos e vivências que nos garantem uma organização de mundo e uma identidade que delimita o corpo, única e exclusivamente, voltadas para o trabalho.

- Expectativa de viver um "eu ideal" produzido por códigos específicos de "ser capaz", demandado por determinada sociedade. 
O Território da Doença Relacionada ao Trabalho: o corpo e a medicina nas LER

- As vivências permeadas pelo medo da perda de referências sociais: medo da perda de identidade, medo da marginalização, medo da exclusão, etc.

- A linha de vida dicotomiza-se entre o normal e o patológico, o útil e o inútil, o trabalhador e o doente, na referência, como já vimos, do ethos da capacidade para o trabalho.

Nessa linha de entendimento, a doença é pensada pela limitação, isto é, como uma vida estratificada, identitária, onde a distinção entre um eu (dado) e um não-eu (perdido ou não encontrado) condiciona a angústia, a ansiedade, a infelicidade, a impotência, o fracasso, a baixa auto-estima. Desses sentimentos fala uma trabalhadora com LER: "não quero ser vista como uma portadora de LER para sempre e tenho medo de que precise esconder a doença para ser aceita novamente como uma boa funcionária”.

Sendo assim, outras questões se colocam: como exceder essas expectativas? Como distinguir a doença mórbida e inútil da resistência de um corpo aos seus constrangimentos? Como escapar às armadilhas de captura? Como pensar (agir) de outro modo?

A idéia de que os acontecimentos permeiam relações de verdade que se sucedem e produzem histórias, e de que outras verdades podem ser produzidas e outras histórias contadas e experimentadas, nos faz pensar que a intervenção de poder no corpo sempre encontra resistências. E, neste caso, como falar das resistências nas LER?

Acreditamos que os sintomas das LER podem ser analisados não como incapacidade ou simulação de um corpo que não quer trabalhar, mas como formas de resistência do corpo aos limites de sua expansão no trabalho. A doença como resistência colocaria em xeque as relações de poder envolvidas na saúde do trabalhador. Possibilitaria, portanto, o questionamento do ritmo intenso do trabalho; enfatizaria a precariedade do processo globalizado em atender às demandas de saúde; apontaria as estratégias de captura de gestos e afetos na delimitação do uso e abuso do corpo na produtividade; configuraria a doença como um sinal, isto é, uma ruptura na continuidade dos constrangimentos do corpo.

Poderíamos reforçar essa idéia com a afirmação de Foucault de que a doença "apaga, mas sublinha; abole de um lado, mas é para exaltar do outro; a essência da doença não está somente no vazio criado, mas também na plenitude positiva das atividades de substituição que vêm preenchê-lo" (1968, p. 24).

A doença pensada como resistência pode ser entendida como uma normatividade, se nos aproximarmos da idéia de Canguilhem (1990), quando 
este afirma que a doença não é somente desequilíbrio ou desarmonia, mas uma forma de busca natural de equilíbrio. Nessa busca de equilíbrio, podemos apreciar que a doença, na relação de trabalho/corpo, joga contra a entropia crescente - no que concerne ao desgaste físico e emocional - e arriscamos a hipótese de uma desaceleração como índice de normatividade. Essa desaceleração criaria uma contranorma ao ritmo, à aceleração e à cadência imposta pelo trabalho que faz adoecer.

Neste sentido, a experiência de viver estaria escapando de uma outra forma de normatividade habituada e aprendida pelos regimes e regras de condução da vida, para atender à demanda de um trabalho de produção hiperacelerada e desgastante. Na teia complexa de relações entre a saúde e a doença, mostra-nos Canguilhem (1990, p. 65):

É artificial dispersarmos a doença em sintomas ou a abstraímos de suas complicações. O que é um sintoma sem contexto? (...) a clínica coloca o médico em contato com indivíduos completos e concretos e não com seus órgãos e suas funções."

Outro olhar e outra escuta que, sem dúvida, não deixariam escapar desse processo de adoecimento o contexto de trabalho que faz o corpo adoecer. Apontamos na contramarcha desse percurso a questão do médico do INSS/ RJ, ao declarar:

"Nós colocamos uma interrogação dizendo que a pessoa não tem uma doença profissional. Ela tem, sim, uma doença orgânica relacionada com características pessoais e particulares, relacionadas com aquela própria pessoa".

\section{Notas}

1 Doutoranda do Centro de Estudos da Saúde do Trabalhador e Ecologia Humana / Escola Nacional de Saúde Pública da Fundação Oswaldo Cruz (CESTEH/ENSP/FIOCRUZ). Professora do Departamento de Psicologia / Universidade Federal Fluminense.

2 Doutor do CESTEH/ENSP/FIOCRUZ.

3 In: Prigogine (1996, p. 12). Ao contrário, argumenta Prigogine, na física do não-equilíbrio, reconhecemos, em todos os níveis de observação, o papel das flutuações e da instabilidade, associadas às escolhas múltiplas e às noções de caos.

\section{Referências Bibliográficas}

BORGES, L. H. Processos de trabalho repetitivos: estudo de caixas bancários. Tese (Doutorado em Psiquiatria) - Instituto de Psiquiatria, Universidade Federal do Rio de Janeiro, 1999. 
BRUNO, F. Membranas e Interfaces. In: VILLAÇA, N. (Org.). Que corpo é esse? Novas perspectivas. Rio de Janeiro: Mauad, 1999.

CANGUILHEM, G. O normal e o patológico. Rio de Janeiro: Forense Universitária, 1990.

FOUCAULT, M. História da sexualidade 3. O cuidado de si. Rio de Janeiro: Graal, 1985.

Vozes, 1977.

. Vigiar e punir: história da violência nas prisões. Petrópolis:

leiro, 1968.

Doença mental e psicologia. Rio de Janeiro: Tempo Brasi-

GONDAR, J. O Trabalho como objeto histórico. Revista NUPSO, Rio de Janeiro, s.n., 1990.

HERZLICH, C. Medicine moderne et quete de sens: la malade signifiant social. In: Le sens du mal: anthopologie, histoire,

sociologie de la malade. Ordres Sociaux. Paris: Presses Universitaire de France, 1986. Cap. V.

LUZ, M. (Coord.). V Seminário do Projeto de Racionalidades Médicas. IMS/UERJ, 1996 (Série Estudos em Saúde Coletiva). Rio de Janeiro: Instituto de Medicina Social/UERJ.

Natural racional e social. Razão médica e racionalidade

científica moderna. Rio de Janeiro: Campus, 1988.

MENDES, R., DIAS, E. Da medicina do trabalho à saúde do trabalhador. Revista de Saúde Pública, São Paulo, v. 25, no 5, p. 341-9, 1991. OLIVEIRA, J., TEIXEIRA, S. (Im)previdência social. São Paulo:

ABRASCO, 1989.

PORTOCARRERO, V. Psiquiatria, liberdade e trabalho: da escravatura à disciplinarização. Revista NUPSO, Rio de Janeiro, s.n., 1990.

RAMAZZINI, B. De Morbis Artificum Diatriba. A doença dos trabalhadores. São Paulo: FUNDACENTRO, 1985.

RIBEIRO, H. P. A violência do trabalho no capitalismo. O caso das lesões dos membros superiores por esforços repetitivos em trabalhadores bancários. Tese (Doutorado em Saúde Pública) - Faculdade de Saúde Pública, Universidade de São Paulo, 1997.

SONTAG, S. A doença como metáfora. Rio de Janeiro: Graal, 1984. WEBER, M. A ética do protestante e o espirito do capitalismo. São Paulo: Pioneira, 1985.

WITKOWSKI, N. (Org.). Ciência e tecnologia hoje. São Paulo: Ensaio, 1997. 
Marilene Affonso Romualdo Verthein - Carlos Minayo Gomez

\section{Documentos}

BRASIL. Lei no 6.367, de 1976. Define a Doença do Trabalho como adquirida ou desencadeada em função de condições especiais em que o trabalho é realizado e com ele se relacione diretamente. Brasília. . MINISTÉRIO DA PREVIDÊNCIA SOCIAL, 1987.

Portaria $n^{\circ}$ 4.062, de 06 de agosto de 1987. Reconhece a tenossinovite como doença do trabalho. Brasília. DELEGACIA REGIONAL DO TRABALHO, 1990.

Portaria no 3.751. Reedita a Norma Regulamentar (NR-17) sobre Ergonomia. Brasília.

. MINISTÉRIO DA PREVIDÊNCIA SOCIAL, 1991. Decreto no 375/91. Reconhece o conjunto das LER como doença do trabalho. Brasília.

INSS. Ordem de Serviço no ${ }^{\circ}$ 149/93. Projeto Estabelecimento de Nexo Técnico. Brasília.

INSS/ DSS. Ordem de Serviço no 251/93. Nexo Técnico.

Brasília.

. MINISTÉRIO DA PREVIDÊNCIA SOCIAL. Decreto $\mathrm{n}^{\mathrm{o}}$

2.172, de 05 de março de 1997. Regulamento dos Benefícios da Previdência Social. Brasília. . MINISTÉRIO DA PREVIDÊNCIA SOCIAL, 1997.

DORT. Norma técnica para a avaliação da incapacidade. Brasília. 
O Território da Doença Relacionada ao Trabalho: o corpo e a medicina nas LER

\section{ABSTRACT}

Disease related to Work: the Body and Medicine in the RSI

The text refers to the classification of "Repetitive Strain Injury" in the category of disease related to work, in 1997, when the National Institute of Social Security decided to change the name from RSI to "Musculoskeletal Disorders Related to Work". It discusses the strategies of denying it as a product of the silence of the body that gets sick because of work. The historical context of the concepts of body and disease, and the several views that, updated, will compose and decompose the movements of creation and/ or crystallization of that territory. Finally, the disease is pointed as the body's resistance to constraints.

Keywords: RSI, subjectivity, the worker's health, Medical Inquiry.

\section{RÉSUMÉ}

La Maladie en rapport avec le Travail: le Corps et la Médécine dans les Maladies du Travail

Le texte prend comme référence la classification des LER dans la catégorie de maladie en rapport avec le travail dévéloppé, en 1997, quand 1'Institut National de Sécurité Sociale a changé le nom LER pour DORT ("Distúrbios Osteomusculares Relacionados ao Trabalho"). On discute les stratégies de dénégation du rapport comme une production de silence du corps qui est malade à cause du labeur. On discute aussi le contexte historique du corps et du concept de maladie, et les plusieurs lectures qui, modernisées, vont composer et décomposer les mouvements de cristallisation et/ou de la création de ce territoire. Finalement, la maladie est considerée une résistance du corps aux contraintes.

Mots-clé: Maladie du travail; subjectivité; santé de l'ouvrier; maîtrise médicin ${ }^{\circ}$

Recebido em 28/09/00.

Aprovado em 20/10/00. 